with it the desired outcomes for patients. Davidson \& Scott are right to be anxious about the quality of what is offered. ${ }^{1}$

1 Davidson K, ScottJ. Does therapists' competence matter in delivering psychological therapy? Psychiatr Bull 2009; 33: 121-3.

2 Whitfield G, Connolly M, Davidson A, Williams C. Use of cognitive-behavioural therapy skills among trained psychiatrists. Psychiatr Bull 2006; 30: $58-60$

3 Roth $\mathrm{AD}$, Pilling S. The Competences Required to Deliver Effective Cognitive and Behavioural Therapy for People with Depression and with Anxiety Disorders. Department of Health, 2007

*Moira Connolly Consultant Psychiatrist and Clinical Director, Gartnavel Royal Hospital, 1055 Great Western Road, Glasgow G12 0XH, email:moira. connolly@ggc.scot.nhs.uk, Tom Brown Consultant Liaison Psychiatrist, Western Infirmary, Glasgow

doi: $10.1192 / p b .33 .8 .315$

Quality of dementia referrals

I was interested to learn from the audit of dementia referrals to a later life psychiatry service that only $13.2 \%$ of referral letters contained Mini-Mental State Examination (MMSE) results. ${ }^{1}$ Findings from a neurology-led dementia service were little better, with around $20 \%$ of referrals from primary care containing evidence of cognitive test results, most commonly the MMSE. ${ }^{2}$ These results contrast with those from a postal survey which claimed $79 \%$ use of dementia screening tests in three English primary care trusts. ${ }^{3}$ How can the discrepancy be accounted for?

It would seem unlikely that genera practitioners (GPs) would not report MMSE results in a referral letter to a dementia service if the test had been undertaken. More likely, the MMSE is too time consuming in primary care and/or too difficult to interpret. If so, then the use of other, briefer, screening instruments with unambiguous cut-offs, such as Mini-Cog or GP-Cog, ${ }^{3}$ must be vigorously encouraged in primary care. No example of their use was encountered in the Fisher \& Larner study. ${ }^{2}$

This could form one aspect of the 'raising awareness' strand in the implementation of the National Dementia Strategy. ${ }^{4}$

1 Hussey D, Foy K, Meehean K. Quality of dementia referrals to later life psychiatry service. Psychiatr Bull 2009; 33: 154-5.
2 Fisher C, LarnerAJ. Frequency and diagnostic utility of cognitive test instrument use by GPs prior to memory clinic referral. Fam Pract 2007; 24 $495-7$.

3 Milne A, Culverwell A, Guss R, Tuppen J, Whelton $R$. Screening for dementia in primary care: a review of the use, efficacy and quality of measures. Int Psychogeriatr 2009; 20: 911-26.

4 Department of Health. LivingWell with Dementia: A National Dementia Strategy. Department of Health, 2009.

Andrew J. Larner Consultant Neurologist, Cognitive Function Clinic, Walton Centre for Curology and Neurosurgery, Lower Lane, Fazakerley, Liverpool L9 7LJ, email: a.larner@ thewaltoncentre.nhs.uk

doi: 10.1192/pb.33.8.316

\section{Web information about electroconvulsive therapy}

Joshi is understandably concerned about the bias to much of the information about electroconvulsive therapy (ECT) that can be found on the internet. ${ }^{1}$ However, he and his patients do not need to look even as far as www. patient.co.uk to find reliable information for services users, carers and families, as the College has a range of such materials available on its website (www.rcpsych.ac.uk/ mentalhealthinformation.aspx). It has gained a reputation for reliable conten written in a style that is accessible to most readers. We have won several commendations at the British Medical Association awards over the past few years and receive consistently complementary feedback from our web readers.

Our ECT page is rather longer than most of our leaflets and perhaps not quite as readable because of the complexity of the issues involved. However, I think it holds up well against most such webpublished information on the subject. Although we do not yet have a printed version, a copy can be printed off the internet. Many of our leaflets are available in paper form and I would commend the readers to have a look at these. They are free to individuals who request them and available to purchase in bulk through the Leaflets Department at the College.

1 Joshi N. Internet electroconvulsive therapy (letter). Psychiatr Bull 2009; 33: 155

Philip W. Timms Consultant Psychiatrist, Chair of the Royal College of Psychiatrists Public Education Committee, START team, South London and Maudsley NHS Foundation Trust, 88 Camberwell Road, London SE11 0EG, email: philip.timms@slam. nhs.uk

doi: $10.1192 / p b .33 .8 .316 a$

\section{What's right for older people}

Hilton's article is a clear and challenging description of the current state of play. ${ }^{1}$ I understand her declaration of interest 'I work in a trust where I perceive older adults' services to be less well-funded relative to services for younger adults' has been deemed controversial by some. How can this be? She is simply stating her perception of things and that perception is congruent with the truth of the matter in every mental health trust in the country, and in every setting in which older people receive sponsored care. ${ }^{2}$

Things were much worse before we created specialist services, when older patients were housed in 50-bed wards and received no therapeutic input. ${ }^{2}$ It was deemed they did not need therapy because they would not benefit from it. Yet older people and those of us who have worked with them have never shouted loudly for equality, preferring to make modest best-use of the resources made available to us.

I was astonished, when working for a while in a learning disability setting, to find that individuals with dependency and behavioural profiles quite commonly seen in old age services were regularly being supported with care-packages costing several times the top rate payable for older people with dementia.

Perhaps now is the time to ask for more.

Sadly, the Healthcare Commission's review ducks the issue, preferring to cite commendable examples of good practice and pursuing the line that age-related services should be abandoned. ${ }^{1}$ That should bury the problem and make it less visible - just as it was when we came in. ${ }^{2}$

1 Hilton C. Psychological therapies, older people and human rights. Psychiatr Bull 2009; 33: $184-6$

2 Healthcare Commission. Equality in Later Life: A National Study of Older People's Mental Health Services. Commission for Healthcare Audit and Inspection, 2009

3 Robb B. Sans Everything: A Case to Answer. Nelson, 1967.

David Jolley Honorary Reader, Consultan Psychiatrist, Personal Social Services Research Unit, Manchester University, Dover Street Building, Dover Street, Manchester M13 9PL, email: David.Jolley@ manchester.ac.uk

doi: $10.1192 / p b .33 .8 .316 b$ 